\title{
Incidental finding of APC deletion in a child: double trouble or double chance? - a case report
}

\author{
Erica Rosina ${ }^{1}$, Berardo Rinaldi ${ }^{1 *}$, Rosamaria Silipigni ${ }^{2}$, Luca Bergamaschi ${ }^{3}$, Giovanna Gattuso $^{3}$, Stefano Signoroni ${ }^{3}$, \\ Silvana Guerneri ${ }^{2}$, Alessandra Carnevali ${ }^{4}$, Paola Giovanna Marchisio ${ }^{1,5}$ and Donatella Milani ${ }^{1}$
}

\begin{abstract}
Background: 22q11.2 deletion syndrome is one of the most common genomic disorders, characterized by the variable presence of facial dysmorphisms, congenital cardiac defects, velopharyngeal insufficiency/cleft palate, thymic hypoplasia/aplasia, immunodeficiency, parathyroid hypoplasia, developmental delay, learning disabilities, psychiatric disorders, renal, ocular, and skeletal malformations, hearing loss and laryngeal abnormalities. Chromosomal microarray (CMA) hybridization is one of the most performed diagnostic tests but as a genome wide analysis, it can point out relevant incidental copy number variations.

Case presentation: We report the case of a 2-year-old boy that came to our attention for mild psychomotor delay, poor growth, and minor facial anomalies. Considering a diagnosis of 22q11.2 deletion syndrome, we performed CMA that not only confirmed our diagnosis, but also pointed out an additional de novo 5q21.3q22.2 microdeletion, encompassing $A P C$ gene. As a result of the genetic testing we enrolled the patient in a tailored surveillance protocol that enabled the early detection of a hepatoblastoma. The child underwent surgical and chemotherapic treatments with complete cancer eradication.

Conclusions: The concurrent finding of an expected result and an additional deletion of APC gene represents an example of a relevant issue about the health and ethical management of secondary findings revealed by genomewide tests. Furthermore, this report highlights the need to develop dedicated surveillance guidelines for children with $A P C$-related polyposis and raise the question whether to suspect and screen for $A P C$-related conditions in cases of sporadic hepatoblastomas.
\end{abstract}

Keywords: 22q11.2 deletion syndrome, APC, Hepatoblastoma, DNA microarray, Incidental finding, Case report

\section{Background}

Nowadays, chromosomal microarray (CMA) represents the first-tier genetic test for patients presenting with intellectual disability (ID) and/or multiple congenital anomalies of unknown origins, detecting DNA copy-number variants $(\mathrm{CNVs})$, i.e. microduplications or microdeletions [1].

\footnotetext{
* Correspondence: berardo.rinaldi@gmail.com

${ }^{1}$ Fondazione IRCCS Ca' Granda Ospedale Maggiore Policlinico, Pediatric Highly Intensive Care Unit, Via della Commenda, 9, 20122 Milan, Italy Full list of author information is available at the end of the article
}

Among the pathogenic CNVs, 22q11.2 deletion syndrome (22q11.2DS) (OMIM \#192430) is one of the most common microdeletion disorders: its incidence is relatively high and it is estimated in 1:4000 newborns, possibly underestimated due to clinical mis/under-recognition. The main clinical findings include facial dysmorphisms, congenital cardiac defects, velopharyngeal insufficiency with or without cleft palate, thymic hypoplasia/aplasia, immunodeficiency and/or autoimmune disorders, parathyroid hypoplasia, developmental delay

C C The Author(s). 2021 Open Access This article is licensed under a Creative Commons Attribution 4.0 International License, which permits use, sharing, adaptation, distribution and reproduction in any medium or format, as long as you give appropriate credit to the original author(s) and the source, provide a link to the Creative Commons licence, and indicate if changes were made. The images or other third party material in this article are included in the article's Creative Commons licence, unless indicated otherwise in a credit line to the material. If material is not included in the article's Creative Commons licence and your intended use is not permitted by statutory regulation or exceeds the permitted use, you will need to obtain permission directly from the copyright holder. To view a copy of this licence, visit http://creativecommons.org/licenses/by/4.0/ The Creative Commons Public Domain Dedication waiver (http://creativecommons.org/publicdomain/zero/1.0/) applies to the data made available in this article, unless otherwise stated in a credit line to the data. 
(commonly borderline intellectual function), learning disabilities, psychiatric disorders, renal, ocular, and skeletal malformations, hearing loss and laryngeal abnormalities [2]. The most common heterozygous microdeletion, leading to DiGeorge/Velocardiofacial syndromes, encompasses $\sim 3 \mathrm{Mb}$, while $8-10 \%$ of individuals show a $\sim 1.5 \mathrm{Mb}$ nested deletion, resulting in similar but overall milder phenotype [3]. In $90 \%$ of cases the deletion occurs sporadically, resulting from a de novo heterozygous deletion, while in the remaining $10 \%$ of individuals it is inherited, in an autosomal dominant pattern, from a parent occasionally showing mild features of the condition [2].

22q11.2DS can be diagnosed using FISH Test (Fluorescence In Situ Hybridization) with specific probes mapping the region, or with whole-genome methodologies, such as CMA. The first one can be beneficial on a strong clinical suspect but it could misdiagnose patients with atypical nested deletions [2]. CMA might be more straightforward for patients with subtle clinical presentation and/or for less experienced health professionals; however, as a genome wide analysis, it can unveil incidental microdeletions/ microduplications, possibly relevant for the patient, that have to be properly communicated and managed.

Here we present a child with clinical suspect of 22q11.2DS and whose diagnostic process led to an incidental genetic finding with important consequences on the clinical management and outcome.

\section{Case presentation}

The male proband is the second child to nonconsanguineous healthy parents of South-American ancestry. The family history is not contributive. Pregnancy was uneventful and the baby was born at term with a weight of $2600 \mathrm{~g}$ (10th centile), length of $48 \mathrm{~cm}$ (25th centile), occipitofrontal circumference (OFC) of $32 \mathrm{~cm}$ (10th centile), Apgar score of 9/10. An umbilical hernia was evident. His growth was normal until 6 months old, when he showed a progressive slowdown. His parents reported frequent infections of upper respiratory tract, treated with antibiotic therapy.

During a hospitalization for a gastroenteritis at the age of 19 months, he underwent a neurological examination that showed a delayed psychomotor development (he could say only one word and he did not walk alone), hypotonia, excessive sleepiness and poor socialization. Magnetic resonance imaging (MRI) of the brain and brainstem revealed minor dysmorphic aspect of ventricular system, asymmetrical and slightly verticalized hippocampi and slightly reduced anterior-posterior diameter of pons. Cardiac and endocrinological evaluation were normal. Routine blood tests showed a microcytic anemia caused by iron deficiency, mild hypoalbuminemia and hypocalcemia. When the child was 21 months old, during a second hospital recovery for herpetic stomatitis, an otorhinolaryngologist evaluation was performed for nocturnal snoring and tonsillectomy was suggested.

For the mild psychomotor delay, poor growth and brain anomalies he was referred to the genetic consultant. On his first genetic evaluation, his weight was $9.5 \mathrm{~kg}(<3 \mathrm{rd}$ percentile) and his head circumference was $46 \mathrm{~cm}(<3 \mathrm{rd}$ percentile). Minor facial anomalies suggestive of 22q11.2DS were observed, including bitemporal constriction, low-set ears, sparse eyebrows, short palpebral fissures, bilateral epicanthic folds, depressed nasal bridge, tubular nose and mild hypoplastic alae nasi (Fig. 1).

Because of the medical history and the facial appearance, a CMA analysis was performed on the patient and his parents. The CMA analysis was performed using a 60-mer oligonucleotide probes technology (SurePrint G3 Human CGH 8x60K, Agilent Technologies, Santa Clara, CA, USA) on DNA extracted from peripheral blood. Labeling, purification and hybridization of DNA samples were carried out according to manufacturer's protocol (Agilent Oligonucleotide Array-Based CGH for Genomic DNA Analysis, version 7.5). Raw data were generated using Agilent Feature Extraction and analyzed by CytoGenomics 4.0.3.12 using ADM-2 algorithm (Agilent Technologies, Santa Clara, CA). To improve the accuracy of the results the Diploid Peak Centralization algorithm was applied.

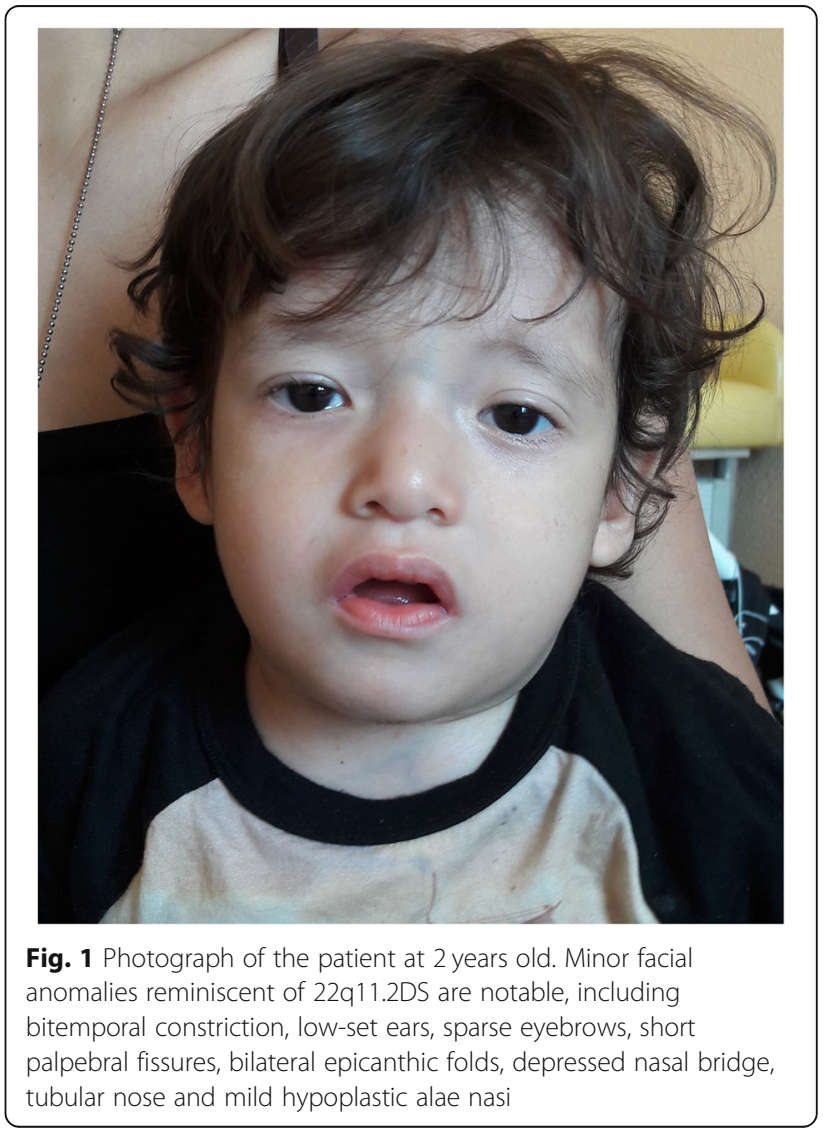


The aberration filter was set to detect a minimum number of 3 consecutive probes/region and the minimum absolute average Log Ratio (MAALR) was $\pm 0,25$. A second analysis was run with a MAALR of $\pm 0,15$ and with a minimum number of 3 probes/region to detect low level mosaicism.

Copy number variations weren't reported if they coincided with published DNA variants listed in the Database of Genomic Variants (http://projects.tcag.ca/ variation/). Genomic coordinates are in accord to the 37 build (March 2009) of the Human Genome Reference consortium (GRch37/hg19).

The analysis detected four rearrangements (Table 1): the small sizes of the two microduplications, their genic content and the parental origins were suggestive for a likely benign role. One de novo rearrangement was a typical 22q11.21 microdeletion associated to the 22q11.2 deletion syndrome (Fig. 2a). Furthermore, a de novo $5 q 21.3 q 22.2$ microdeletion was identified: this $3.6 \mathrm{Mb}$ deletion involves 12 OMIM genes, including $A P C$, delineating a condition of $A P C$-associated polyposis (Fig. 2b).

As a result of the genetic test the proband was enrolled for a tailored follow-up. At the first evaluation, an abnormally high alpha-fetoprotein $(\alpha F P)$ level was detected $(266.4 \mu \mathrm{g} / \mathrm{L}$, normal range $<7 \mu \mathrm{g} / \mathrm{L})$ and the abdomen ultrasound showed a solid mass of $4 \times 3 \mathrm{~cm}$ in the left lobe of the liver, with well-defined edges, ovular and bilobate shape (Fig. 3). For a more accurate evaluation of the lesion, a magnetic resonance (MRI) of the abdomen was performed and it confirmed the presence of a liver mass, in II-III-IV segment. It appeared irregularly hyperintense in T2-wheighted images and hypointense in T1, with multinodular structure and a delimiting pseudocapsule, hypointense in both T2 and T1 sequences. The endovenous paramagnetic contrast agent showed an irregular enhancement that increased in venous phase, with persisting hyperdense strie in the late-phase. This lesion, according to the irregular pattern of enhancement, structure and vessel relation, was compatible with a diagnosis of hepatoblastoma (HB).

The patient then was referred to the Pediatric Oncology Unit of Istituto Nazionale dei Tumori. Clinical examination was unremarkable. Blood investigations confirmed an increased $\alpha$ FP level $(97.5 \mu \mathrm{g} / \mathrm{L})$; beta human chorionic gonadotropin hormone ( $\beta$ hCG) value was normal. Chest $\mathrm{x}$-ray was normal, without evidence of any thoracic lesion. Considering these assessments, a core-needle biopsy of the mass was performed and a diagnosis of fetal epithelial hepatoblastoma was made.

Following this diagnosis, the child was treated according to the current guidelines for very low risk hepatoblastoma patients. First of all, a left hepatic lobectomy was performed (resection of segments II-III), without any post-surgical complications. Histological examination confirmed the diagnosis and the radicality of the surgery (fetal epithelial hepatoblastoma; mitotic index > 2/10 high power fields (HPF); tumor-free resection margins). After that, considering the histological evidences, two cycles of adjuvant chemotherapy with cisplatin (100 $\mathrm{mg} / \mathrm{m}^{2}$ in a continuous intravenous 48 - $\mathrm{h}$ infusion) were administered with a 21 days interval, starting 1 month after surgery. The $\alpha F P$ values gradually decrease during therapy and finally normalized 2 months after the end of chemotherapy. The treatment was not complicated by haematological or other toxicities except for an episode of upper respiratory tract infection, after the first cycle of chemotherapy, probably favoured by the predisposition determined by 22q11.2DS.

Eighteen months after the end of treatment, the child had no evidence of tumor recurrence. He continued with a periodical specific oncological follow-up including clinical evaluation, radiological assessment (abdominal ultrasonography) and serum $\alpha \mathrm{FP}$ dosage; besides, he was referred to specialists of inherited gastrointestinal cancer syndromes for the appropriate FAP surveillance. He also continued the genetic follow-up with hematologic tests, eye examination and thyroid ultrasound. At the latest evaluation, thyroid functional parameters were altered: he was referred to the endocrinologist for appropriate diagnostic framework and treatment.

\section{Discussion and conclusions}

The array-CGH analysis confirmed the clinical suspect of 22q11.2DS and led to an incidental finding of a cancer predisposition syndrome due to the deletion of the $A P C$ gene.

Table 1 Summary of patient's CNVs detected by chromosomal microarray

\begin{tabular}{|c|c|c|c|c|c|c|}
\hline Chromosome region & Copy number variation & Size & Breakpoints $^{a}$ & $\begin{array}{l}\text { OMIM disease-causing } \\
\text { genes involved }\end{array}$ & Inheritance & Role \\
\hline $2 q 34$ & Duplication & $432 \mathrm{~kb}$ & $210,021,463-210,453,149$ & / & Father & Likely benign \\
\hline $5 q 21.3 q 22.2$ & Deletion & $3.6 \mathrm{Mb}$ & $108,730,323-112,313,646$ & SLC25A4, WDR36, APC & De novo & Pathogenic \\
\hline $7 q 21.12$ & Duplication & 307 kb & $87,811,283-88,118,091$ & ADAM22 & Mother & Likely benign \\
\hline $22 q 11.21$ & Deletion & $2.5 \mathrm{Mb}$ & $18,919,942-21,440,514$ & $\begin{array}{l}\text { PRODH, SLC25A1, CDC45L, GP1BB, } \\
\text { TBX1, TXNRD2, COMT, TANGO2, } \\
\text { RTN4R, SCARF2, PI4KA, HCF2 }\end{array}$ & De novo & Pathogenic \\
\hline
\end{tabular}

${ }^{\mathrm{a}}$ The breakpoints are reported according to the 37 build (March 2009) of the Human Genome Reference consortium (GRch37/hg19) 


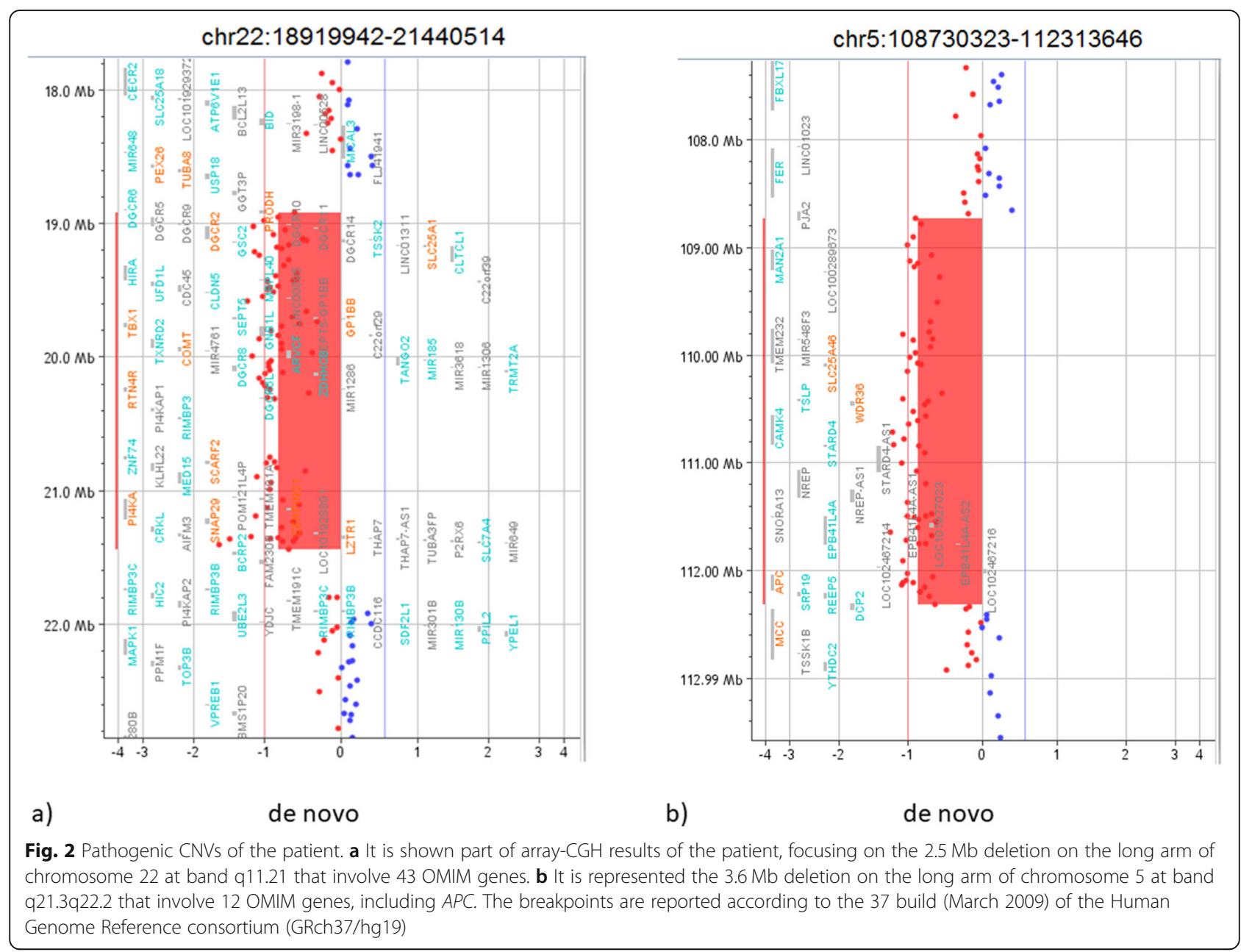

Germline haploinsufficiency of the $A P C$ gene cause familial adenomatous polyposis (FAP), a highly penetrant condition characterized by development of various rectal and colonic adenomas and early-onset colorectal cancer [4]. The majority of disease-causing alterations of the APC gene are loss-of-function single nucleotide variants [5]; large cytogenetic deletions, containing $A P C$ gene, have been rarely reported and it is estimated that they account for $2-3 \%$ of patients $[6,7]$. The APC gene germline mutations and deletions are not only involved in colorectal tumorigenesis, but also in other various premalignant and malignant lesions: duodenal, jejunal and gastric polyps, papillary thyroid carcinomas, desmoid tumors and embryonal tumors, such as hepatoblastoma (HB) and medulloblastoma. Whole $A P C$ gene deletions seem to cause mainly classical-FAP phenotype, with thousands of adenomatous colonic polyps and high frequency of extraintestinal FAP related manifestations such as upper gastrointestinal polyps, congenital hypertrophy of the retinal pigment epithelium (CHRPE) and desmoid tumors $[6,8,9]$.
The 22q11.2 microdeletion identified in our proband could explain the clinical features of delayed psychomotor development, hypotonia, poor socialization, frequent episodes of infectious diseases, abnormal findings at electroencephalogram and encephalic MRI, hypocalcemia and hypothyroidism and characteristic facial dysmorphisms. Although 22q11.2DS has not been clearly associated with an increased risk of malignancy, few cases of pediatric cancers have been reported among these patients [10-12]: in particular Scattone et al. [10] and McDonald-McGinn et al. [12] described respectively one and two patients with 22q11.2DS and hepatoblastoma. The distinctive immunodeficiency, predisposing to higher rate of infectious diseases also from carcinogenic viruses and to impaired tumor surveillance, together with the heterozygous deletions of some specific genes involved in detoxification of carcinogenic substances (such as catechol-O-methyltransferase gene) are possible concurrent causes in the complex process of carcinogenesis [11]. 


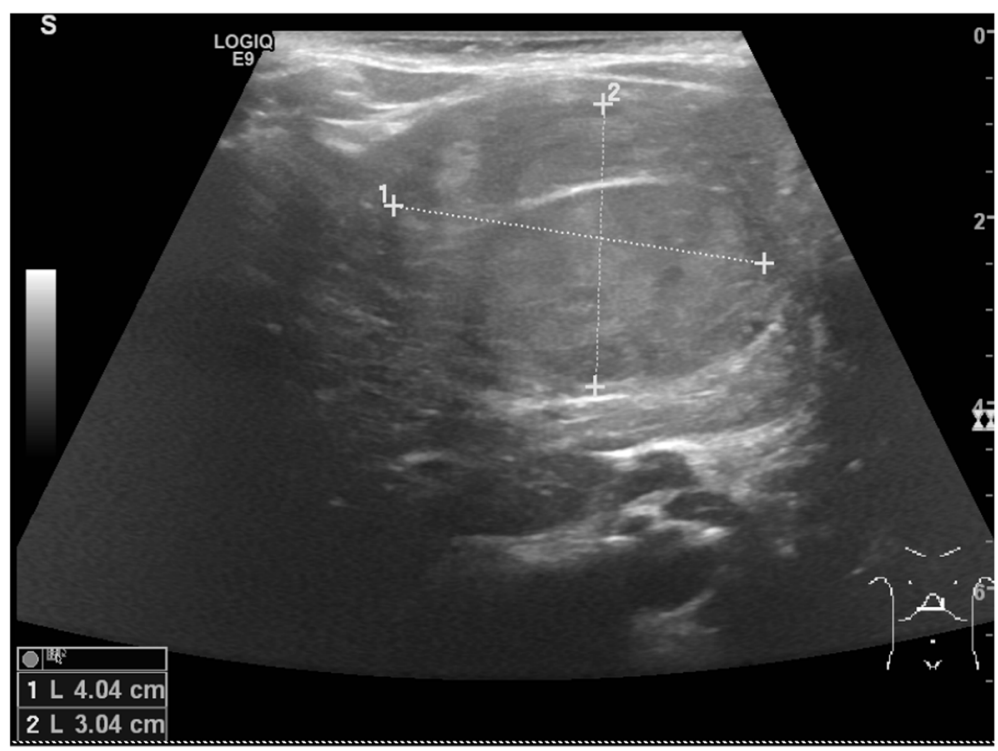

Fig. 3 Abdomen ultrasound scan of the patient's liver showing the hepatoblastoma. The figure shows a scan of the abdominal ultrasonography of the patient: it revealed a solid mass of $4 \times 3 \mathrm{~cm}$ in the left lobe of the liver, with well-defined edges, ovular and bilobate shape

In this scenario, 22q11.2DS might have contributed to the HB development along with APC deletion that remain the prevalent predisposing factor for our patient. In fact, the increased risk of developing $\mathrm{HB}$ in patients carrying a constitutional mutation or deletion of $A P C$ is estimated to be really low, ranging from 0.3 to $1.6 \%$ [13], but it is approximately 750-7500 times higher the prevalence of general population $(0.0001 \%)$ [14]. The median age at diagnosis of HB in FAP children is similar to that of sporadic ones, predominantly between 6 months and 3 years of age [15]. Since the prognosis of HB is strictly dependent on early detection and, consequently, on the complete resection, screening test in patients with germline haploinsufficiency of $A P C$ is mandatory. Beyond increasing survival, it could allow less-intensive therapy and less organ toxicity. To date, there is not a standard agreement regarding time and method of surveillance. Given the estimated risk, similar to other genetic predisposing conditions (such as Beckwith-Wiedemann syndrome), several studies suggest $\alpha F P$ level monitoring in conjunction with hepatic ultrasound at least every 3 months [16], until 7 years of age [13-17].

This and previous reports also bring into question whether to suspect and screen for $A P C$-related conditions in cases of sporadic hepatoblastomas. HB accounts for about $1 \%$ of all pediatric tumors and represents the most common liver cancer in childhood: if our case had not been tested before, his HB would be classified as "sporadic" one, as he had no suggestive family history or other manifestations of FAP. Aberrant activation of Wnt-signaling pathway occurs in the vast majority of HBs through somatic mutations at beta-catenin gene
(CTNNB1, OMIM "116806), particularly point mutations or in-frame deletions involving exon 3 [16-18]; APC protein is a key negative regulator of $W n t$-signaling pathway. The reported rate of germline $A P C$ mutations in apparently sporadic HBs is highly variable: Sumazin et al. [18] found approximately $1,1 \%$ of sporadic HBs with an $A P C$ germline mutation, while Aretz et al. [15] and Young et al. [19] reported an incidence of $10-20 \%$, therefore suggesting routine $A P C$ testing of all patients with HB. Since somatic CTNNB1 and germline $A P C$ mutations have been shown to occur in a mutually exclusive manner in hepatoblastomas and in all tumor types studied so far [18-20], the identification of a somatic activating CTNNB1 mutation in an HB patient directly reduces the risk of carrying a germline $A P C$ mutation [20]. Based on these data, a two-step approach would be preferable: testing for somatic mutations of CTNNB1, trough immunochemistry and/or genetic analyses on tumor blocks, should be performed firstly; then all CTNNB1-negative patient should undergo screening for germline APC mutation/deletion with a combination of sequencing methods and MLPA (multiplex ligationdependent probe amplification). This must be a first-tier analysis instead in cases with extra-liver FAP manifestations or a suggestive family history.

Like $A P C$, many other genes and correlated syndromes have a well-known increased risk to cancer in pediatric age; at least $8-10 \%$ of them reveal a germline mutation in cancer predisposition genes known at this days, with $A P C$ as the second most frequent mutated gene in this type of patients [21]. Detailed guidelines for genetic analyses in apparently sporadic childhood cancers are 
missing: testing all pediatric cancer patient for germline cancer predisposition genes could be a waste in resources and most importantly could lead to a notable number of unknown significant variants with the consequent massive family impact that these type of "uncertain diagnoses" bring with them. Instead, as the first step, somatic tumor screening can not only provide information about distinct molecular risk subtype and help clinical management, but it can also aid in distinguishing sporadic tumors from those related to a genetic predisposition syndrome.

Our case is a perfect example of genetic "double diagnosis" made with a genomic testing like CMA: if we would confirm the clinical suspect of 22q11.2DS using FISH technique, we would miss the $A P C$ deletion with important repercussion on the patient's care. Nowadays, genome-wide tests, such as CMA and whole exome sequencing (WES), have not only considerably increased the diagnostic yield but the rate of unexpected and uncertain findings as well. Talking about CMA, an incidental finding could be defined as unexpected CNVs not directly related to the patient's clinical indication that has however some medical implications, conferring susceptibility to cancer, neurodegenerative adult-onset pathologies or revealing a carrier status. These incidental findings are also relevant for the repercussions on other family members, often leading to critical testing in healthy-appearing individuals and raising emblematic ethical dilemmas such as testing siblings in childhood [22]. While, for exome and genome sequencing, whether and which incidental variants must be reported is an ongoing discussion topic [23], the contribution of CNVs is under-explored especially considering that it is currently used as the first diagnostic tool. Some large studies have investigated the proportion of incidental CNVs and their genetic counselling implications [24-27]. In particular, based on a literature meta-analysis by Talukdar et al., the incidence of CNVs involving cancer susceptibility genes (CSGs) in individuals that underwent CMA is $0.6 \%$ [17]. According this UK consensus group, microdeletions encompassing $A P C$ are categorised as "recognised deletion/duplication syndrome involving a cancer susceptibility gene with a demonstrable elevated lifetime risk of cancer evident from the literature, for which surveillance is recommended", for which laboratory report is mandatory [17]. In the Italian setting, specific recommendations for this topic are lacking; however we strongly believe that, in pre-test counselling, the medical geneticist must inform, with an appropriate consent form, the patient or his parents about the possible incidental findings and they can freely decide whether to know. However if the patient's willpower of not knowing is more acceptable for adult-onset diseases with no therapy or preventive care, finding an incidental CNVs that could lead to therapeutic/prevention measures, especially for children, open a strong ethical problem for clinicians [27]. For our case, not reporting the $A P C$ deletions would have been morally difficult and worrying for the patient's health; and this made us realise how much international guidelines for incidental CNVs report are needed.

In conclusion, this report presents a 22q11.2DS child with an additional deletion in $A P C$ discovered with CMA. Involving a cancer predisposing condition, this incidental finding let us disclose it to the family, leading to an early diagnosis of hepatoblastoma and to its complete eradication. This case highlights some emerging health management and ethical issues about current genomewide tests and incidental findings, even more notable being these analyses available also for non-genetic healthcare professionals. In this scenario, a tight collaboration among the different healthcare professionals involved in clinical management appears essential.

\section{Abbreviations}

22q11.2DS: 22q11.2 deletion syndrome; aFP: Alpha-fetoprotein; ßhCG: Beta human chorionic gonadotropine hormone; CMA: Chromosomal microarray; CNVs: Copy-number variants; CSGs: Cancer susceptibility genes; FAP: Familial adenomatous polyposis; FISH: Fluorescence In Situ Hybridization; HPF: High power fields; HB: Hepatoblastoma; ID: Intellectual disability; MAALR: Minimum absolute average Log Ratio; MRI: Magnetic resonance imaging;

OFC: Occipitofrontal circumference; WES: Whole exome sequencing

\section{Acknowledgements}

This work has been generated within the European Reference Network on Rare Congenital Malformations and Rare Intellectual Disability (ERN-ITHACA).

\section{Authors' contributions}

DM evaluated the patient, coordinated the diagnostic and follow-up process, and took care of the conception and design of the study. ER collected the information and drafted the initial manuscript. BR and DM critically reviewed and revised the manuscript. RS and SG carried out the chromosomal microarray analysis, interpretation of the data and drafted the methods. LB, GG and SS provided the patient's neoplastic treatment and helped to draft the manuscript. AC performed abdomen ultrasound. PGM critically revised the manuscript and supervised patient management. All authors read and approved the final manuscript.

\section{Funding \\ No funding}

\section{Availability of data and materials}

Data sharing is not applicable to this article as no datasets were generated or analysed during the current study.

Ethics approval and consent to participate

Parental informed consent for publication was obtained.

\section{Consent for publication}

Written informed consent was obtained from the patient's legal guardians for publication of this case report and any accompanying images.

\section{Competing interests}

The authors declare that they have no competing interests.

\section{Author details}

${ }^{1}$ Fondazione IRCCS Ca' Granda Ospedale Maggiore Policlinico, Pediatric Highly Intensive Care Unit, Via della Commenda, 9, 20122 Milan, Italy.

${ }^{2}$ Fondazione IRCCS Ca' Granda Ospedale Maggiore Policlinico, Laboratory of 
Medical Genetics, Milan, Italy. ${ }^{3}$ Pediatric Oncology Unit, Fondazione IRCCS Istituto Nazionale dei Tumori, Milan, Italy. ${ }^{4}$ Department of Radiology, Fondazione IRCCS Ca' Granda Ospedale Maggiore Policlinico, Milan, Italy. ${ }^{5}$ Department of Pathophysiology and Transplantation, University of Milan, Milan, Italy.

Received: 2 July 2020 Accepted: 11 January 2021

Published online: 15 February 2021

\section{References}

1. Miller DT, Adam MP, Aradhya S, Biesecker LG, Brothman AR, Carter NP, et al. Consensus statement: chromosomal microarray is a first-tier clinical diagnostic test for individuals with developmental disabilities or congenital anomalies. Am J of Hum Genet. 2010;86:749-64.

2. McDonald-McGinn DM, Emanuel BS, Zackai EH, et al. 22q11.2 deletion syndrome. 1999 Sep 23 [updated 2020 Feb 27]. In: Adam MP, Ardinger HH Pagon RA, et al., editors. GeneReviews ${ }^{\oplus}$. Seattle: University of Washington, Seattle; 1993-2020.

3. Burnside RD. 22q11.21 deletion syndromes: a review of proximal, central, and distal deletions and their associated features. Cytogenet Genome Res. 2015;146(2):89-99.

4. Kerr SE, Thomas CB, Thibodeau SN, Ferber MJ, Halling KC. APC germline mutations in individuals being evaluated for familial adenomatous polyposis: a review of the mayo clinic experience with 1591 consecutive tests. J Mol Diagn. 2013;15:31-43.

5. Hirschman BA, Pollock BH, Tomlinson GE. The spectrum of APC mutations in children with hepatoblastoma from familial adenomatous polyposis kindreds. J Pediatr. 2005;147:263-6.

6. Aretz S, Stienen D, Uhlhaas S, Pagenstecher C, Mangold E, Caspari R, et al. Large submicroscopic genomic APC deletions are a common cause of typical familial adenomatous polyposis. J Med Genet. 2005;42(2):185-92.

7. Wachsmannova L, Mego M, Stevurkova V, Zajac V, Ciernikova S. Novel strategies for comprehensive mutation screening of the APC gene. Neoplasma. 2017;64(3):338-43.

8. Quadri M, Vetro A, Gismondi V, Marabelli M, Bertario L, et al. APC rearrangements in familial adenomatous polyposis: heterogeneity of deletion lengths and breakpoint sequences underlies similar phenotypes. Familial Cancer. 2015;14:41-9.

9. Michils G, Tejpar S, Thoelen R, van Cutsem E, Vermeesch JR, Fryns J-P, et al. Large deletions of the APC gene in 15\% of mutation-negative patients with classical polyposis (FAP): a Belgian study. Hum Mutat. 2005;25(2):125-34.

10. Scattone A, Caruso G, Marzullo A, Piscitelli D, Gentile M, Bonadonna L, et al. Neoplastic disease and deletion 22q11.2: a multicentric study and report of two cases. Pediatr Pathol Mol Med. 2003;22:323-41.

11. Stevens T, van der Werff ten Bosch J, De Rademaeker M, Van Den Bogaert A, van den Akker M. Risk of malignancy in 22q11.2 deletion syndrome. Clin Case Rep. 2017;5:486-90.

12. McDonald-McGinn DM, Reilly A, Wallgren-Pettersson C, Hoyme HE, Yang SP, Adam MP, et al. Malignancy in chromosome 22q11.2 deletion syndrome (DiGeorge syndrome/velocardiofacial syndrome). Am J Med Genet A. 2006; 140(8):906-9.

13. Achatz MI, Porter CC, Brugières L, Druker $H$, Frebourg $T$, Foulkes WD, et al. Cancer screening recommendations and clinical management of inherited gastrointestinal cancer syndromes in childhood. Clin Cancer Res. 2017;23: e107-14.

14. Krawczuk-Rybak M, Jakubiuk-Tomaszuk A, Skiba E, Plawski A. Hepatoblastoma as a result of APC gene mutation. J Pediatr Gastroenterol Nutr. 2012;55:334-6.

15. Aretz S, Koch A, Uhlhaas S, Friedl W, Propping P, Von Schweinitz D, et al. Should children at risk for familial adenomatous polyposis be screened for hepatoblastoma and children with apparently sporadic hepatoblastoma be screened for APC germline mutations? Pediatr Blood Cancer. 2006;47:811-8.

16. Trobaugh-Lotrario AD, López-terrada D, Li P, Feusner JH. Hepatoblastoma in patients with molecularly proven familial adenomatous polyposis : clinical characteristics and rationale for surveillance screening. Pediatr Blood Cancer. 2018;65:e27103

17. Talukdar S, Hawkes L, Hanson H, Kulkarni A, Brady AF, Mcmullan DJ, et al. Structural aberrations with secondary implications (SASIs): consensus recommendations for reporting of cancer susceptibility genes identified during analysis of copy number variants (CNVs). J Med Genet. 2019:56:71826.
18. Sumazin $P$, Chen $Y$, Treviño $L R$, Sarabia SF, Hampton OA, Patel $K$, et al Genomic analysis of hepatoblastoma identifies distinct molecular and prognostic subgroups. Hepatology. 2017;65(1):104-21.

19. Yang A, Sisson R, Gupta A, Tiao G, Geller Jl. Germline APC mutations in hepatoblastoma. Pediatr Blood Cancer. 2018;65:e26892.

20. Dubbink HJ, Hollink IHIM, Avenca Valente C, et al. A novel tissue-based Bcatenin gene and immunohistochemical analysis to exclude familial adenomatous polyposis among children with hepatoblastoma tumors. Pediatr Blood Cancer. 2018;65:e26991.

21. Zhang J, Walsh MF, Wu G, Edmonson MN, Gruber TA, Easton J, et al. Germline mutations in predisposition genes in pediatric Cancer. N Engl J Med. 2015;373:2336-46.

22. Brodeur GM, Nichols KE, Plon SE, Schiffman JD, Malkin D. Pediatric Cancer predisposition and surveillance: an overview, and a tribute to Alfred G. Knudson Jr. Clin Cancer Res. 2017:23:e1-5.

23. Green RC, Berg JS, Grody WW, Kalia SS, Korf BR, Martin CL, et al. ACMG recommendations for reporting of incidental findings in clinical exome and genome sequencing. Genet Med. 2013;15(7):565-74.

24. Pichert G, Mohammed SN, Ahn JW, Ogilvie CM, Izatt L. Unexpected findings in cancer predisposition genes detected by array comparative genomic hybridisation: what are the issues? J Med Genet. 2011;48(8):535-9.

25. Boone PM, Soens ZT, Campbell IM, Stankiewicz P, Cheung SW, Patel A, et al. Incidental copy-number variants identified by routine genome testing in a clinical population. Genet Med. 2013;15(1):45-54.

26. Hamm JA, Mikhail FM, Hollenbeck D, Farmer M, Robin NH. Incidental detection of cancer predisposition gene copy number variations by array comparative genomic hybridization. J Pediatr. 2014;165(5):1057-9 e1-4.

27. Lefebvre M, Sanlaville D, Marle N, Thauvin-Robinet C, Gautier E, Chehadeh $\mathrm{SE}$, et al. Genetic counselling difficulties and ethical implications of incidental findings from array-CGH: a 7-year national survey. Clin Genet. 2016;89(5):630-5.

\section{Publisher's Note}

Springer Nature remains neutral with regard to jurisdictional claims in published maps and institutional affiliations.

Ready to submit your research? Choose BMC and benefit from

- fast, convenient online submission

- thorough peer review by experienced researchers in your field

- rapid publication on acceptance

- support for research data, including large and complex data types

- gold Open Access which fosters wider collaboration and increased citations

- maximum visibility for your research: over $100 \mathrm{M}$ website views per year

At BMC, research is always in progress.

Learn more biomedcentral.com/submissions 